\title{
Trends in incidence of gallbladder cancer - Indian scenario
}

This article was published in the following Dove Press journal:

Gastrointestinal Cancer:Targets and Therapy

27 January 2011

Number of times this article has been viewed

\author{
Nandagudi Srinivasa Murthy' \\ Dinesh Rajaram' \\ MS Gautham' \\ NS Shivraj' \\ Sreekantaiah Pruthvish' \\ Preethi Sara George ${ }^{2}$ \\ Aleyamma Mathew ${ }^{2}$
}

'MS Ramaiah Medical College, Bangalore, Karnataka, India; ${ }^{2}$ Regional Cancer Centre, Thiruvananthapuram, Kerala, India
Correspondence: Aleyamma Mathew Division of Statistics and Epidemiology, Regional Cancer Centre, Thiruvananthapuram 695 0II,

Kerala, India

Email amathew@rcctvm.org
Background: Reports of increasing incidence rates of gallbladder cancer in several areas in India prompted the analysis of time trends. The present communication reports its geographic and gender distribution and trends in occurrence of this disease over time.

Materials and methods: The data published in Cancer Incidence in Five Continents for various Indian registries for different periods and/or publication by the individual registries served as the source material. Mean annual percentage change (MAPC) in incidence rates was computed using relative difference between two time periods (earliest and latest), and estimation of annual percent change (EAPC) was computed by log-linear regression model.

Results: In 1998-2006, incidence rates of gallbladder cancer (age-standardized rate, ASR) were high in Delhi and Kamrup ((3.6 and 7.4) and (5.3 and 14.3) per 10 person years in males and females, respectively) and lowest in Aurangabad, 0.0 in both genders. The incidence rate revealed an increase in all registries. MAPC in ASR ranged from 1.0\% to 8.10\%. EAPC for Mumbai, Chennai, and Bangalore for the period 1983-2002 revealed statistically significant increase in crude, age-standardized, and truncated rate (TR) (35-64 years) incidence rates. The largest EAPC in ASR was in Chennai (almost 6.0\% in both genders) and smallest in Mumbai (3.5\% and $2.1 \%$ in males and females, respectively).

Conclusions: Statistically significant increase in gallbladder cancer incidence rates has been reported for Mumbai, Chennai, and Bangalore. Further studies are required in identifying factors that may be operative in etiology of cancer of gallbladder.

Keywords: gallbladder cancer, trend, Indian scenario, calendar year

\section{Introduction}

Gallbladder cancers arise in the epithelium and are classified as carcinomas. The incidence of this type of cancer is low when compared with other sites, even among populations who are at highest risk, and accounts for about $1 \%$ of all cancer deaths. It has been reported that during 2008, the incident cases of gallbladder cancer at the global level were 145,662 with an age-standardized rate (ASR) of 2.0 per $10^{5}$ person years. ${ }^{1}$ Incidence varies geographically with higher rates in certain areas of Latin America (Colombia, Peru, and Ecuador), Japan, and Eastern Europe (Poland, the Czech Republic, Slovakia, Hungary, and the former East Germany). In North America, high rates of gallbladder cancer have been noted in Hispanic and American Indian populations. ${ }^{2}$ In high-risk populations, the incidence among women is approximately double than that of men. In India, during 2001, the estimated number of gallbladder cancer was 14,986 and is likely to increase to 23,750 by 2016 as a result of aging and increase in size of the population. ${ }^{3}$ As the incidence of this disease is submit your manuscript $\mid$ www.dovepress.com

Dovepress

DOI: $10.2147 /$ GICTT.SI6578
Gastrointestinal Cancer:Targets and Therapy 201 I:I I-9

(C) 201 I Murthy et al, publisher and licensee Dove Medical Press Ltd. This is an Open Access article which permits unrestricted noncommercial use, provided the original work is properly cited. 
increasing, a systematic trend analysis may help to understand the alterations in incidence with regard to time, place and person distribution, and changing cancer risk. The present communication makes an attempt to analyze the time trends of gallbladder cancer for Indian population by year of diagnosis and age.

\section{Material and methods}

Incidence rates (ASR to the world-standard population, crude rate [CR], truncated rate [TR; 35-64 years], as well as ASIR) for gallbladder cancers between 1968 and 2002 were obtained from volumes III to IX of Cancer Incidence in Five Continents (CI5)., ${ }^{2,-9}$ The CI5 included incidence data reported by the Population-Based Cancer Registries (PBCRs) covering areas Ahmedabad, Bangalore, Chennai, Delhi, Mumbai, Nagpur, Pune, Thiruvananthapuram (Trivandrum), and Karunagapalli. Volumes III-IX generally provided data for 5-year time periods: 1968-1972, 1973-1977, 1978-1982, 1983-1987, 1988-1992, 1993-1997, and 1998-2002, respectively. The Bangalore data for 1998-2002 and for registries such as Bangalore, Mumbai, Bhopal, Barshi, New Delhi, Chennai data for 2004-2005; Kolkata for 2005; North Eastern registries for 2005-2006; Ahmedabad rural for 2005, Nagpur, Pune, and Aurangabad for 2001 were obtained from the individual registry reports or from the reports of the National Cancer Registry Programme of Indian Council of Medical Research (ICMR). ${ }^{10-13}$

Data from 1968 to 2002 were available only for Bombay (Mumbai) registry. The Bangalore and Chennai registries which were established during 1982 provided data for four successive 5-year calendar periods from 1983 to 2002. Limited data were available from Ahmedabad registry. The Nagpur and Pune registries although had data for long term, however, data were missing for some in-between 5-year periods. Delhi registry provided data for three successive 5-year periods.

The trend component was studied by calculating mean annual percentage change (MAPC) in the CR, age-standardized incidence rate, and ASIR through regression modeling of data.

\section{MAPC using CR, age-standardized incidence rate, or ASIR}

In this approach, the trend component has been isolated according to 1) 5-year calendar period and by 2) considering age of both genders along with the calendar period. Data for Bangalore and Chennai relate to periods 1983-1987 and 1998-2002, Mumbai 1968-1972 and 1998-2002, Nagpur 1980-1982 and 1998-2002, Pune 1973-1977 and 1998-2002,
Ahmedabad 1983-1987 and 1993-1997, and Delhi 1988-1992 and 1998-2002. Karunagapalli and Thiruvananthapuram (Trivandrum) registries were not considered for trend analysis as they had data for only two 5-year periods.

Measures of trend over time have been estimated as overall or MAPC\% in ASR and ASIR. Mathematically, it is expressed as follows: MAPC $\%=(($ Incidence rate at latest time period $t$ - Incidence rate at base-line period $\left.t_{0}\right) /$ (Incidence rate at base-line period $t_{0} \times$ number of actual years covered between the two time periods) $\times 100$. The pooled ASIR was estimated for the age groups 15-34 years, 35-44 years, 45-54 years, 55-64 years, and above 65+ years to have more stabilized incidence rates.

\section{Estimated annual percent change using regression model}

Annual percent changes in incidence rates of cancer using CR, ASR, and TR (35-64 years) were estimated by means of a log-linear regression model. The logarithm of the respective incidence rates on the midpoint of the 5-year time period was considered. The mathematical expression was of the form $\log _{\mathrm{e}}$ (incidence rate) $=\alpha_{0}+\alpha_{1} a+\beta y$, where $a$ is age, $y$ is year of diagnosis, $\alpha_{0}$ is a constant, and $\alpha_{1}$ and $\beta$ are regression coefficients. The coefficients including the average annual change in incidence rate were calculated from the maximum likelihood estimate of the parameter for the year of diagnosis $(\beta)$. Further, estimation of annual percent change (EAPC) was done as $\mathrm{EAPC}=100 \times\left(e^{\beta}-1\right)$. This change was regarded as statistically significant if the $P$ value was $\leq 0.05$. For the purpose of uniformity and comparison, published data from Mumbai, Chennai, and Bangalore were employed for the five periods from 1983 to 2002. Satisfactory fit in terms of a linear model was obtained with a Poisson error distribution for the number of incidence cases. Separate analysis was performed with the age terms being retained in the model. Quadratic term $\left(a^{2}\right)$ was added and retained if there was a substantial improvement in the model in terms of deviances.

\section{Results \\ Age-standardized incidence rates of gallbladder cancer}

The ASR of gallbladder cancer during the period 1998-2006 ranged from 0.3 (Karunagapalli) to 5.3 (Kamrup urban district) per $10^{5}$ men, whereas it varied between 0.4 (Trivandrum and Barshi) and 14.3 (Kamrup urban district) per $10^{5}$ women excepting for Aurangabad (Table 1). The highest ASR among men and women was observed in Kamrup 
Table I Age-adjusted incidence rate of gallbladder cancer in Indian registries

\begin{tabular}{|c|c|c|c|c|}
\hline \multirow[t]{2}{*}{ Registry } & \multirow[t]{2}{*}{ Type of registry } & \multirow[t]{2}{*}{ Period } & \multicolumn{2}{|c|}{ ASR (per $\left.10^{5}\right)$} \\
\hline & & & Males & Females \\
\hline Aurangabad"I & Urban & 2001 & 0.0 & 0.0 \\
\hline Bangalore $^{10}$ & Urban & 2004-2005 & I.I & $\mathrm{I} .4$ \\
\hline Mumbai (Bombay) ${ }^{10}$ & Urban & 2004-2005 & 1.6 & 2.6 \\
\hline Bhopal $^{10}$ & Urban & 2004-2005 & 2.3 & 4.3 \\
\hline Delhi' ${ }^{10}$ & Urban & 2004-2005 & 3.6 & 7.4 \\
\hline Chennai (Madras) $)^{10}$ & Urban & 2004-2005 & 1.2 & 0.9 \\
\hline Kolkata ${ }^{2}$ & Urban & 2005 & 1.2 & 3.4 \\
\hline Nagpur"I & Urban & 2001 & I.I & 1.2 \\
\hline Trivandrum ${ }^{2}$ & Urban & $1998-2002$ & 0.6 & 0.4 \\
\hline Pune" & Urban & 2001 & 0.9 & 1.2 \\
\hline Ahmedabad ${ }^{10}$ & Rural & 2004-2005 & 1.1 & 0.5 \\
\hline Barshi $^{10}$ & Rural & 2004-2005 & 1.0 & 0.4 \\
\hline Karunagapalli ${ }^{2}$ & Rural & $1998-2002$ & 0.3 & 0.9 \\
\hline Dibrugarh $^{10}$ & Urban and rural & $2005-2006$ & 2.4 & 6.9 \\
\hline Kamrup urban district ${ }^{10}$ & Urban and rural & $2005-2006$ & 5.3 & 14.3 \\
\hline Silchar town $n^{10}$ & Urban and rural & $2005-2006$ & 2.3 & 4.7 \\
\hline Imphal west district ${ }^{10}$ & Urban and rural & $2005-2006$ & 4.0 & 10.0 \\
\hline Mizoram state ${ }^{10}$ & Urban and rural & $2005-2006$ & 1.3 & 2.4 \\
\hline Sikkim state ${ }^{10}$ & Urban and rural & $2005-2006$ & 2.3 & 4.7 \\
\hline
\end{tabular}

Abbreviation: ASR, age-standardized rate.

urban district (Assam) followed by Imphal West District and Delhi. Kamrup urban district had the highest ASR of gallbladder cancer in both gender. The data showed that the incidence rate of gallbladder cancer is high in north and eastern India among both genders, and comparison of ASRs of gallbladder cancers indicated differences in the occurrence of this cancer among registries.

\section{ASIRs of gallbladder cancer}

ASIR was observed to be high after the age of 45 . The highest ASIR was recorded in Delhi and was found to be 22.08 in males and 35.67 in females, respectively, per $10^{5}$ persons after the age of 65 years. Observations revealed a very distinct age-related pattern among both genders. The incidence is comparatively very low in age groups below 45 . Incidence rates increased with increasing age at 45 years and peaks after $65+$ years (Table 2).

\section{Time trends in occurrence of gallbladder cancer}

\section{Period effect}

There has been an increase in MAPC in all registries. In Mumbai, during the various 5-year calendar periods, ASR of gallbladder cancer has revealed almost monotonic increasing trend. The ASR was 0.5 and 0.60 per $10^{5}$ person-years in males and females during the period 1968-1972 and increased to 1.60 and 2.30 during 1998-2002, respectively
(Table 3). MAPC in ASR was found to be $6.29 \%$ and $8.10 \%$ in males and females, respectively. Data from the other two registries located in the state of Maharashtra, namely, Nagpur and Pune, also revealed an increasing trend with a higher increase in MAPC in females compared to males over the years in the incidence of gallbladder cancer.

In Bangalore, the MAPC based on ASR was $6.25 \%$ in males and $5.0 \%$ in females, and in Chennai, the corresponding values were $5.0 \%$ in males and $3.0 \%$ in females. Ahmedabad, Mumbai, and Pune registries indicated a higher increase in MAPC in females compared to males over the years. In all the registries excepting Delhi, higher MAPC was observed among CR compared to ASR.

\section{Age and periodwise incidence rates}

The ASIR by period revealed an increase in the incidence of the disease in many age groups in various registries. The MAPC was highest in the age group of 45-54 (males) in Chennai and Nagpur registries which were $10.96 \%$ and $10.00 \%$, respectively, whereas in females, MAPC showed variation in age groups for various registries. For the highest age group of $65+$ years in males, the MAPC ranged from $1.64 \%$ to $14.69 \%$, whereas in females, it ranged from $0.49 \%$ (Nagpur) to $86.56 \%$ (Bangalore) in the various registries. Further, in many of the registries, increase in MAPC was noted in all the age intervals. Ahmedabad registry revealed a decrease in MAPC $\%$ among males in the earlier age intervals, 
Table 2 ASIR per $10^{5}$ persons of gallbladder cancer in India

\begin{tabular}{lllllllll}
\hline Age (years) & Bangalore & Chennai & Delhi & Mumbai & Nagpur & Pune & Trivandrum & Karunagapalli \\
\hline Males & & & & & & & & \\
$15-34$ & 0.05 & 0.02 & 0.30 & 0.10 & 0.11 & 0.08 & 0.8 & - \\
$35-44$ & 0.77 & 0.93 & 2.04 & 0.82 & 0.41 & 0.42 & 1.4 & - \\
$45-54$ & 1.60 & 1.61 & 6.11 & 2.32 & 1.93 & 1.10 & 2.1 & 2.0 \\
$55-64$ & 2.65 & 4.18 & 15.36 & 4.99 & 3.30 & 3.32 & 4.8 & 3.2 \\
$65+$ & 5.54 & 4.45 & 22.08 & 10.66 & 2.91 & 6.39 & 5.6 & 5.1 \\
Females & & & & & & & & \\
$15-34$ & 0.06 & 0.09 & 0.71 & 0.19 & 0.05 & 0.09 & 0.4 & - \\
$35-44$ & 0.74 & 0.60 & 5.99 & 1.79 & 0.65 & 0.71 & - & \\
$45-54$ & 1.49 & 1.50 & 19.64 & 3.93 & 2.69 & 1.80 & 1.2 & \\
$55-64$ & 2.65 & 3.37 & 30.52 & 7.89 & 2.56 & 2.95 & 2.8 & \\
$65+$ & 7.01 & 3.82 & 35.67 & 13.05 & 1.90 & 8.59 & 8.1 & 6.2 \\
\hline
\end{tabular}

Copyright (C) 2007. Adapted with permission from Curado MP, Edwards B, Shin HR, et al, (eds). Cancer Incidence in Five Continents. Vol IX. Lyon, France: International Agency for Research on Cancer; 2007. IARC Scientific Publication No 160.

Abbreviation: ASIR, age-specific incidence rate.

whereas among females, it showed an increase in all the age groups (Tables 4 and 5).

\section{EAPC in incidence through regression analysis}

EAPC was attempted between the period and incidence rates for 1) CR, 2) ASR, and 3) TR (35-64 years) for the data of three PBCRs, namely, Mumbai, Chennai, and Bangalore for the period 1983-2002. Results of the analysis revealed that for all the above rates, linear regression was found to be a satisfactory fit between period and incidence rate as noted through the deviance/df values (Table 6). Statistically significant increase in EAPC was noted with CR, ASR, and TR among registries. The estimated EAPC in CR and ASR ranged from $4.12 \%$ to $7.37 \%$ and $3.53 \%$ to $6.05 \%$ in males and $4.04 \%$ to $8.46 \%$ and $2.15 \%$ to $6.13 \%$ in females, respectively, among the three registries and was found to be statistically significant ( $P$ value was 0.0001 in males, and in females, it ranged from 0.0001 to 0.01 ).

\section{Discussion}

The present trend analysis has revealed a steady increase in the incidence rate of gallbladder cancer from almost all the registries, though at a higher rate in North and Eastern India among both genders. ASIRs revealed an increasing incidence after the age of 45 years and peaks after the age of 65 years.

The absolute number of new cancer patients in India is increasing rapidly due to an increase in the size of the population as well as an increase in the proportion of elderly persons due to improved life expectancy. ${ }^{14}$ The reports of various Indian registries suggested that the gallbladder cancer is more common in northern India (Delhi and Bhopal) extending all over from east to west (Kolkata, North East, and Maharashtra). Among women, it is the 4th common cancer in Delhi, 5th in Bhopal, and 10th in Mumbai. ${ }^{10}$ In the present analysis, time trends in the incidence of gallbladder cancer have been examined using the data published by CI5 for the Indian population-based registries established in the country. Cancer registry data in India is reliable, and thus, the data were published in CI5. ${ }^{9}$

Changing trends in the incidence of gallbladder cancer may occur from a variety of factors such as initiation of screening program, changes in diagnostic methods, completeness and reliability of data, changing profile of risk factors in the population, or as a consequence of better health awareness. Modeling of the data through age, birth cohort, and calendar time period is the appropriate technique for analyzing trends in cancer. However, the above approach could not be adopted in the present analysis, as the data were not available for a sufficiently long period of time from various registries other than Mumbai. Hence, MAPC using CR, ASR, TR, and ASIR of gallbladder cancer was computed between the earliest and latest time periods to evaluate the changes over the time period. Additionally, EAPC through log-linear regression model for gallbladder cancer was computed for CR, ASR, and TR from the data of three registries, namely, Mumbai, Chennai, and Bangalore. There has been an increase in MAPC over time period in all registries. The ASIR by period revealed an increase in the incidence of the disease in many age groups, but increase in MAPC was highest in the age group of 45-54 years. Statistically significant increase in EAPC was noted with CR, ASR, and TR in all the registries from 1983 to 2002.

The ASR was lower in southern India when compared to northern and eastern India. The highest incidence rate 


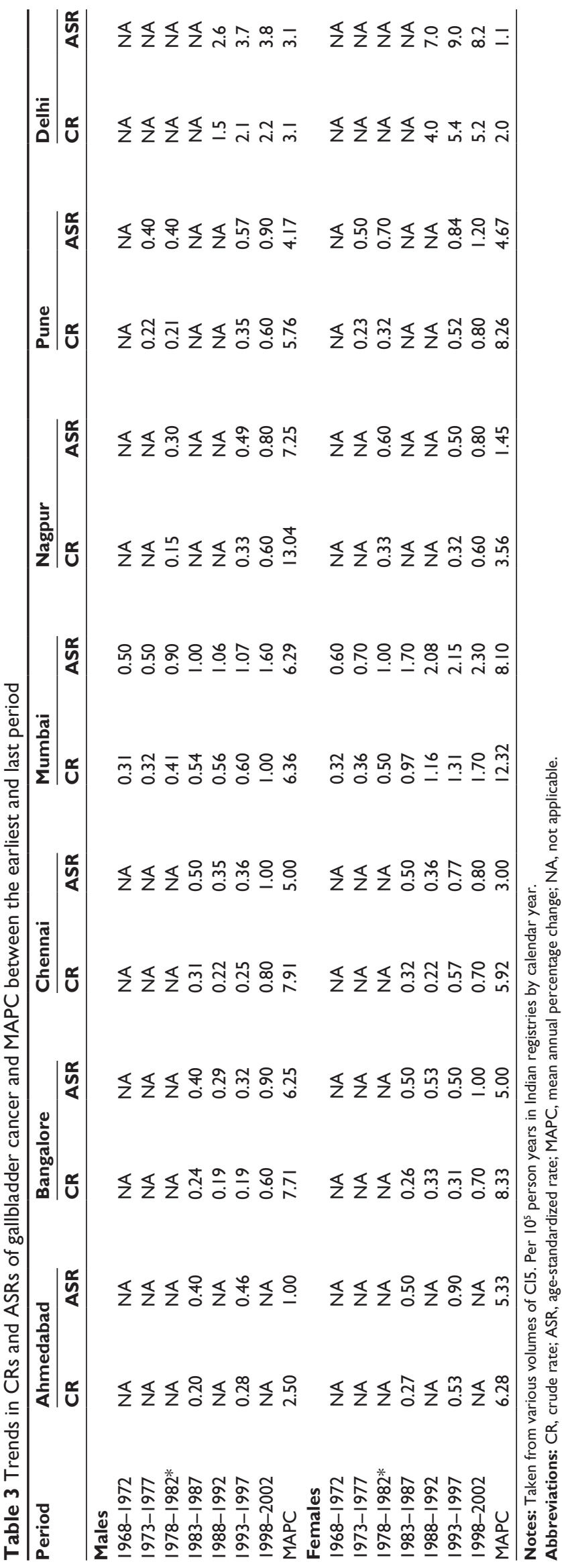

in these geographical areas was observed in Delhi in both genders apart from the North Eastern registries. Data on the incidence rate of gallbladder cancer for various registries also suggested that in areas with lower incidences rate of gallbladder cancer, the female:male ratio of incidence rates is either 1 or lower. This means that in these areas, the incidence of gallbladder cancer among men is either equal to or higher than women. Similar findings have been reported by other researchers. ${ }^{15}$

The report of the ICMR-WHO project on development of a cancer atlas in India also showed that the minimum age-standardized incidence rate of gallbladder cancer were higher in many north Indian states such as Uttar Pradesh and Bihar even though there are no PBCRs. Hospital data from Varanasi and Patna suggested a higher occurrence of gallbladder cancer in these areas. ${ }^{16}$ With changing lifestyle in several areas of India, it is possible that the incidence rate of gallbladder cancer may increase in the country. The data suggested that when incidence rate of gallbladder cancer rises, it would occur among younger persons; in addition, female to male ratio may also rise. In a study carried out to assess the lifetime risk for development of 10 major cancers in India and its trends over the years 1982-2000, statistically significant $(P<0.05)$ increasing trends have been observed for gallbladder cancers among females. ${ }^{17}$

Since gallbladder is part of the gastrointestinal tract, it is plausible that dietary factors could contribute to the etiology of cancer of this organ. ${ }^{18-20}$ A meta-analysis conducted on obesity and the risk of gallbladder cancer revealed that those who were overweight had a relative risk of $1.15(95 \%$ confidence interval [CI]: 1.01-1.30) and 1.66 (95\% CI: 1.47-1.88) males and females, respectively. Similarly, the association with obesity was stronger for women (relative risk: 1.88 ; 95\% CI: $1.66-2.13$ ) than for men (relative risk: 1.35 ; $95 \%$ CI: $1.09-1.68) .{ }^{21}$

Direct evidence that obesity increases the risk of gallbladder cancer comes from several studies. ${ }^{22-24}$ A study in Poland found total energy intake was related to gallbladder cancer with an odds ratio (OR) of 2.00 (95\% CI: 1.10-3.70) for the highest versus the lowest quartile. ${ }^{25} \mathrm{~A}$ case-control study in Chilean population found a weakly direct association for high consumption of fried foods and gallbladder cancer. ${ }^{26}$ A positive association of high-fat intake with gallbladder cancer risk was found in a case-control study in Karachi. ${ }^{27}$ An increased amount of fat or adipose tissue in an overweight or obese person probably influences the development of cancer by releasing several hormone-like factors or adipokines. Majority of adipokines 


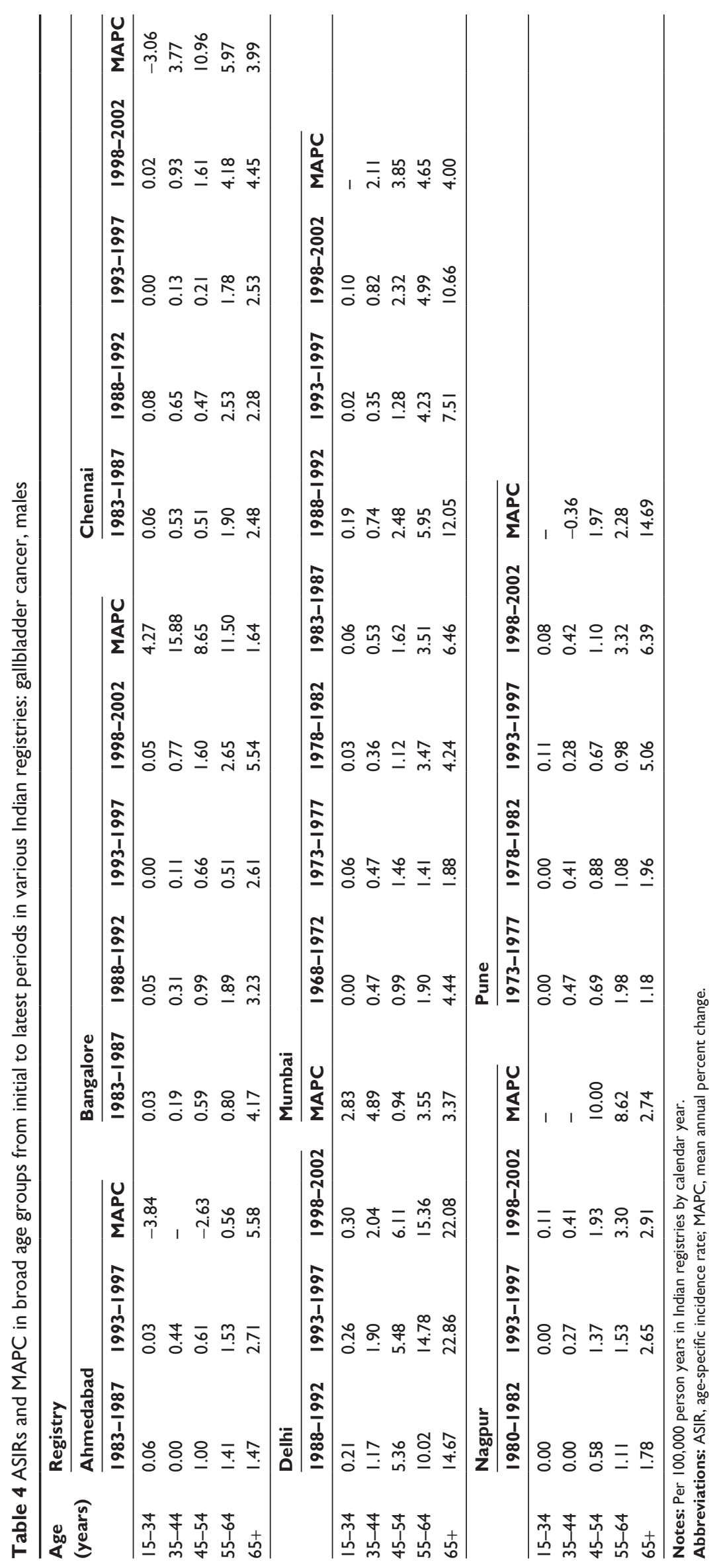




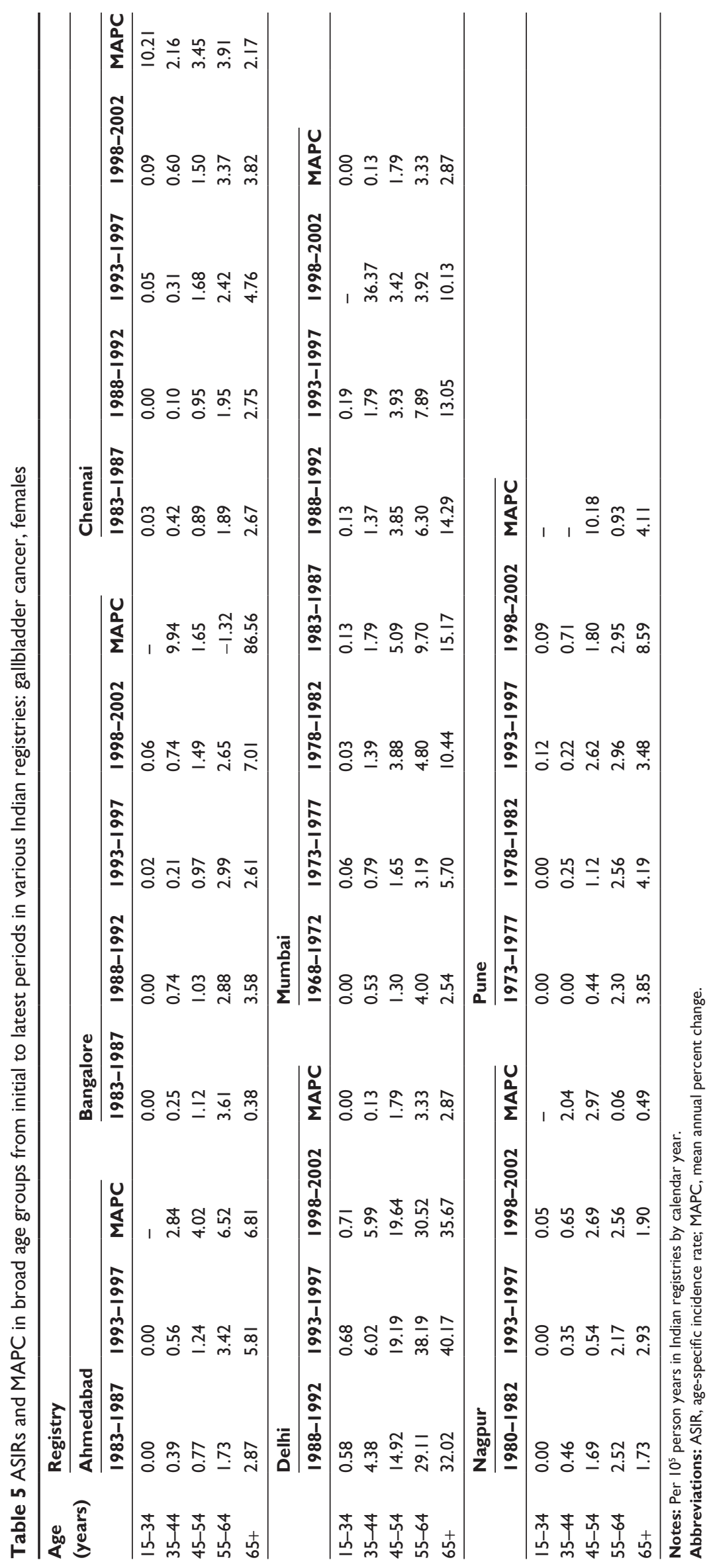


Table 6 EAPC in CR, ASR, and TR for gallbladder cancer for both sexes in various registries

\begin{tabular}{|c|c|c|c|c|c|c|c|c|c|}
\hline \multirow{3}{*}{$\begin{array}{l}\text { Age } \\
\text { (years) }\end{array}$} & EAPC (\%) & $P$ value & Deviance/df & EAPC (\%) & $P$ value & Deviance/df & EAPC (\%) & $P$ value & Deviance/df \\
\hline & \multicolumn{9}{|l|}{ Registry } \\
\hline & Mumbai & & & Chennai & & & Bangalore & & \\
\hline \multicolumn{10}{|l|}{ Males } \\
\hline$C R$ & 4.123 & 0.001 & 0.043 & 7.069 & 0.001 & 0.107 & 7.369 & 0.001 & 0.199 \\
\hline ASR & 3.531 & 0.001 & 0.046 & 6.046 & 0.001 & 0.088 & 5.306 & 0.001 & 0.153 \\
\hline TR & 2.912 & 0.001 & 0.067 & 5.411 & 0.001 & 0.151 & 4.991 & 0.04 & 0.375 \\
\hline \multicolumn{10}{|c|}{ Females } \\
\hline $\mathrm{CR}$ & 4.039 & 0.001 & 0.024 & 8.459 & 0.001 & 0.185 & 5.601 & 0.001 & 0.259 \\
\hline ASR & 2.153 & 0.001 & 0.031 & 6.131 & 0.001 & 0.134 & 4.634 & 0.01 & 0.222 \\
\hline TR & 2.480 & 0.001 & 0.052 & 5.792 & 0.01 & 0.342 & 1.319 & 0.30 & 0.118 \\
\hline
\end{tabular}

Abbreviations: EAPC, estimated annual percentage change; CR, crude rate; ASR, age-standardized rate; TR, truncated rate.

are proinflammatory, which promote pathological conditions like insulin resistance and cancer. ${ }^{28}$

A case-control study in Chilean population found a weakly direct association for high consumption of fried foods and gallbladder cancer. ${ }^{26} \mathrm{~A}$ positive association of high-fat intake with gallbladder cancer risk was found in a casecontrol study in Karachi. ${ }^{27}$ It has been shown that alcohol is associated with an increased risk of gallstones. ${ }^{20}$ Further, it has been stated that the etiology of the gallbladder cancer is much less clear. ${ }^{18}$

The well-established risk factor for gallbladder cancer is a history of gallstones. ${ }^{22,29}$ Obesity has shown to be an important risk factor for development of gallbladder cancer, while adequate intake of fruits and vegetables have been shown to be a protective factor. Findings from various studies on the adequate consumption of vegetables indicated an inverse association with gallbladder cancer risk. ${ }^{20,30}$ Low intake of fresh fruits has been shown to be associated with an increased risk of gallbladder cancer with OR of 6.40 (95\% CI: $1.40-30.30) .{ }^{26}$ Consumption of vegetables and fruits in higher amounts has been found to be associated with a reduced risk of many cancers. ${ }^{31}$ Several large populationbased and observational epidemiological studies have highlighted the importance of vegetables and fruits in reducing the risk of cancer in a variety of organs and tissues. It has been shown that cereals, vegetables, fruits, pulses, spice, and other plant foods contain many micronutrients such as vitamins and minerals including phytochemicals, which have chemoprevention properties. ${ }^{31,32}$

In conclusion, gallbladder cancer is becoming one of the most common cancers among women in north and northeast India. The data on gallbladder cancer incidence rates have increased over time in Mumbai, Delhi, and in various other registries. Incidence rates have increased in all the age groups. From the study, it has been observed that the increase in incidence is not specific to any cohort and etiological/ risk factors as the increase in the incidence rate affected all the age groups. Although the increase occurred among both genders, it affected women to a higher extent than the men. Before the problem reaches epidemic proportion, we need coordinated and focused research toward understanding of the etiology, early detection, and better treatment for the typical presentation of advanced gallbladder cancer.

\section{Acknowledgments}

The authors acknowledge with thanks the Director General, Indian Council of Medical Research, New Delhi, India, and Principal and Dean, M.S. Ramaiah Medical College and Hospitals, Bangalore, for all the support and encouragement.

\section{Disclosure}

The authors report no conflicts of interest in this work.

\section{References}

1. Ferlay J, Shin HR, Bray F, Forman D, Mathers C, Parkin DM. GLOBOCAN 2008, Cancer Incidence and Mortality Worldwide. Lyon, France: International Agency for Research on Cancer; 2010. IARC CancerBase No 10.

2. Curado MP, Edwards B, Shin HR, et al, editors. Cancer Incidence in Five Continents. Vol IX. Lyon, France: International Agency for Research on Cancer; 2007. IARC Scientific Publication No 160.

3. Murthy NS. Trends and patterns of cancer load in India in epidemiological estimation and analysis, mimeographed, submitted to Indian Council of Medical Research (ICMR), New Delhi, India. 2009.

4. Waterhouse JAH, Muir CS, Correa P, Powell J, editors. Cancer Incidence in Five Continents. Vol III. Lyon, France: International Agency for Research on Cancer; 1976. IARC Scientific Publication No 15.

5. Waterhouse JAH, Muir CS, Shanmugaratnam K, Powell J, editors. Cancer Incidence in Five Continents. Vol IV. Lyon, France: International Agency for Research on Cancer; 1982. IARC Scientific Publication No 42.

6. Muir CS, Waterhouse JAH, Mack T, Powell J, Whelan SL, editors. Cancer Incidence in Five Continents. Vol V. Lyon, France: International Agency for Research on Cancer; 1987. IARC Scientific Publication No 88. 
7. Parkin DM, Muir CS, Whelan SL, Gao YT, Ferlay J, Powell J, editors. Cancer Incidence in Five Continents. Vol VI. Lyon, France: International Agency for Research on Cancer; 1992. IARC Scientific Publication No 120.

8. Parkin DM, Whelan SL, Ferlay J, Raymond L, Young J, editors. Cancer Incidence in Five Continents. Vol VII. Lyon, France: International Agency for Research on Cancer; 1997. IARC Scientific Publication No 143.

9. Parkin DM, Whelan SL, Ferlay J, Teppo L, Thomas DB, editors. Cancer Incidence in Five Continents. Vol VIII. Lyon, France: International Agency for Research on Cancer; 2002. IARC Scientific Publication No 155.

10. National Cancer Registry Programme. Two Year Report of Population Based Cancer Registries 2004-2005: Incidence and Distribution of Cancer. Mumbai, India: Indian Council of Medical Research; 2008.

11. Cancer Incidence and Patterns in Urban Maharashtra-2001. Report to the State of Maharashtra on Status on Cancer. Mumbai, India: Cancer Registry Division, Indian Cancer Society; 2007.

12. Population Based Cancer Registry, Biennial Report, 2000 and 2001. Bangalore, India: Department of Epidemiology and Bio-Statistics, Kidwai Memorial Institute of Oncology; 2004.

13. Population Based Cancer Registry, Biennial Report, 2002. Bangalore, India: Department of Epidemiology and Bio-Statistics, Kidwai Memorial Institute of Oncology; 2005.

14. Murthy NS, Mathew A. Cancer epidemiology, prevention and control. Curr Sci. 2004;86(4):518-527.

15. Chaudhry K. Gall bladder cancer-Indian scenario. Indian J Med Paediatr Oncol. 2007;28(2):6-15.

16. Nandakumar A, Gupta PC, Gangadharan P, Visweswara RN, Parkin DM. Geographic pathology revisited: development of an atlas of cancer in India. Int J Cancer. 2005;116(5):740-754.

17. Satyanarayana L, Asthana S. Life time risk for development of ten major cancers in India and its trends over the years 1982 to 2000. Indian J Med Sci. 2008;62(2):35-44.

18. WCRF and AICR. Food, Nutrition and the Prevention of Cancer: A Global Perspective. Washington, DC: World Cancer Research Fund and American Institute for Cancer Research; 1997.

19. Rai A, Mohapatra SC, Shukla HS. A review of association of dietary factors in gallbladder cancer. Indian J Cancer. 2004;41(4):147-151.
20. Tyagi BB, Manoharan N, Raina V. Risk factors for gallbladder cancer: a population based case-control study in Delhi. Indian J Med Paediatr Oncol. 2008;29(1):16-26.

21. Larsson SC, Wolk A. Obesity and the risk of gallbladder cancer: a meta-analysis. Br J Cancer. 2007;96(9):1457-1461.

22. Strom BL, Soloway RD, Rios-Dalenz JL, et al. Risk factors for gallbladder cancer. An International Collaborative Case-Control Study. Cancer. 1995;76(10):1747-1756.

23. Potter JD. Food, Nutrition and the Prevention of Cancer: A Global Perspective. Washington, DC: American Institute of Cancer Research; 1997:198-201.

24. Lazcano-Ponce EC, Miquel JF, Munoz N, et al. Epidemiology and molecular pathology of gallbladder cancer. CA Cancer J Clin. 2001;51(6):349-364.

25. Zatonski WA, Lowenfels AB, Boyle P, et al. Epidemiologic aspects of gallbladder cancer: a case-control study of the SEARCH Program of the International Agency for Research on Cancer. J Natl Cancer Inst. 1997;89(15):1132-1138.

26. Serra I, Yamamoto M, Calvo A, et al. Association of chili pepper consumption, low socioeconomic status and longstanding gallstones with gallbladder cancer in a Chilean population. Int $J$ Cancer. 2002;102(4):407-411.

27. Rizvi TJ, Zuberi SJ. Risk factors for gallbladder cancer in Karachi. J Ayub Med Coll Abbottabad. 2003;15(3):16-18.

28. Murthy NS, Mukherjee S, Ray G, Ray A. Dietary factors and cancer chemoprevention: an overview of obesity-related malignancies. J Postgrad Med. 2009;55(1):45-54.

29. Kapoor VK, McMichael AJ. Gallbladder cancer: an 'Indian' disease. Natl Med J India. 2003;16(4):209-213.

30. Pandey M, Shukla VK. Diet and gallbladder cancer: a case control study. Eur J Cancer Prev. 2002;11(4):365-368.

31. Ray A, Ray GN, Murthy NS. Cancer chemoprevention and lifestyle factors: an overview of epidemiology and biological mechanisms. In: Arora R, editor. Cancer Chemo-Prevention and Therapeutic Perspectives. New Delhi, India: JAYPEE Brothers Medical Publishers (P) Ltd; 2009:122-146.

32. Krishnaswamy K, Polasa K. Non-nutrients and cancer prevention. ICMR Bull. 2001;31:1-9.
Gastrointestinal Cancer: Targets and Therapy

\section{Publish your work in this journal}

Gastrointestinal Cancer: Targets and Therapy is an international, peer-reviewed, open access journal focusing on gastro-intestinal cancer research, identification of therapeutic targets and the optima use of preventative and integrated treatment interventions to achieve improved outcomes, enhanced survival and quality of life for the

\section{Dovepress}

cancer patient. The manuscript management system is completely online and includes a very quick and fair peer-review system. Visit http://www.dovepress.com/testimonials.php to read real quotes from published authors 